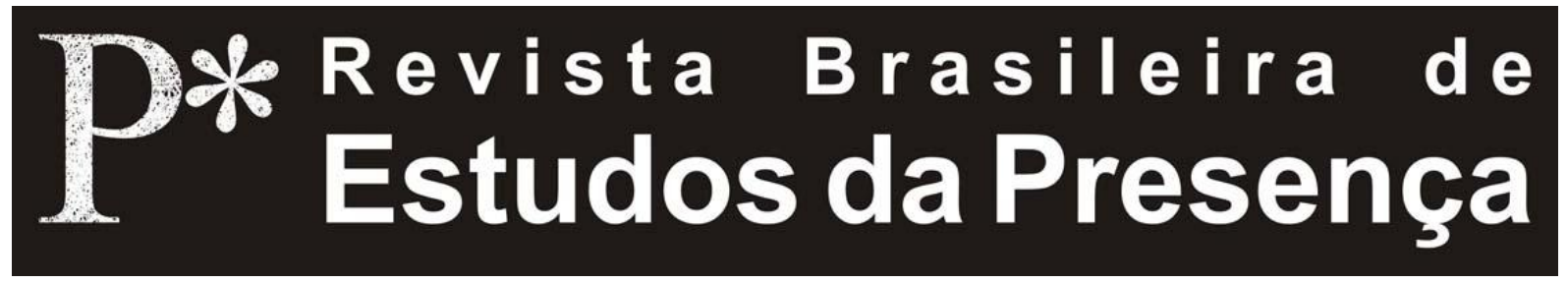

\title{
Arte, Biopolítica e Resistência
}

\author{
Carminda André \\ Universidade Estadual Paulista "Júlio de Mesquita Filho" - UNESP
}

RESUMO - Arte, Biopolítica e Resistência - Na obra Em Defesa da Sociedade, Michel Foucault apresenta a ideia de que houve, em certo momento da história do ocidente europeu, a interiorização da guerra nos modos de organização social. De que teria havido um deslocamento do valor da guerra para a política, positivando-a, legitimando a própria guerra como um modo de governar e, por consequência, como modo de vida. Nesse viés, Foucault observa que a política que se desenvolve nos Estados Modernos é a guerra continuada por outros meios. Governa-se para manter a guerra. Este ensaio discute alguns impactos desse discurso no campo das artes.

Palavras-chave: Subjetividade. Biopolítica. Arte de Rua. Resistência.

ABSTRACT - Art, Biopolitics and Resistance - In Society Must Be Defended, Michel Foucault presents the idea that there was at one point in the history of western Europe, the internalization of the war in the modes of social organization. That would have been a value shift from war to politics, asserting it, legitimizing the war itself as a way of governing and, therefore, as a way of life. In this vein, Foucault notes that the policy is developed in the Modern is war continued by other means. Governors to keep the war. This essay discusses some impacts of this discourse in the arts.

Keywords: Subjectivity. Biopolitics. Street Art. Resistance.

RÉSUMÉ - L'Art, la Biopolitique et la Résistance - Dans Il fault défendre la société, Michel Foucault présente l'idée qu'il y avait à un moment dans l'histoire de l'Europe occidentale, l'intériorisation de la guerre dans les modes d'organisation sociale. Cela aurait été un changement de la valeur de la guerre à la

Carminda André, Arte, Biopolítica e Resistência.

R.bras.est.pres., Porto Alegre, v.1, n.2, p. 426-442, jul./dez., 2011.

Disponível em http://www.seer.ufrgs.br/presenca 
politique, c'est affirmer, légitimer la guerre elle-même comme une façon de gouverner et, par conséquent, comme un mode de vie. Dans cette veine, note Foucault que la politique est développée dans la guerre moderne est poursuivi par d'autres moyens. Gouverneurs de garder la guerre. Cet essai discute des impacts de ce discours dans les arts.

Mots-clés: La Subjectivité. La Biopolitique. Street Art. De la Résistance.

Desde o início do século XX, com a instalação da política higienista, importada dos norte-americanos, a rua tem sido produzida como lugar temeroso, lugar de vagabundos, lugar das trocas ilícitas na cidade de São Paulo. Chegamos a um ponto em que a população aceita ser vigiada por dispositivos panóticos em nome de sua segurança para caminhar nas ruas. Contentamo-nos em usar a rua como um lugar de passagem, um lugar para carros. Mas essa realidade tem sido produzida dentro de um pacote maior: trata-se de uma política para governar a vida dos cidadãos em seus detalhes. Fato este que Michel Foucault chamou de biopolítica. Controlam-se os comportamentos não só em espaços públicos, mas, cada vez mais, os comportamentos são normatizados em sua privacidade.

A rua tornou-se lugar impessoal e, ao mesmo tempo, lugar de proprietário. É na rua que meninas despreparadas para a maternidade deixam seus bebês em latas de lixo; é na rua que encontramos sem-tetos com todo tipo de história pessoal, é na rua que estão os viciados - crianças, jovens ou adultos - que a família já não consegue controlar. $\mathrm{Na}$ rua estão os descuidados. Mas, é na rua também que podemos encontrar alta tecnologia para a disciplinarização da movimentação da população.

O controle de espaços públicos - tais como praças, ruas, parques -, sinalizam uma vida comunitária ausente. Observo uma síndrome do medo, alimentada pelo noticiário, confinando a população em suas casas. A lenta intromissão do Estado, por meio de leis, para dentro da vida privada, é sinal de ausência de espírito. Já temos a lei da palmada que legisla os modos de educação dos pais

Carminda André, Arte, Biopolítica e Resistência.

R.bras.est.pres., Porto Alegre, v.1, n.2, p. 426-442, jul./dez., 2011.

Disponível em http://www.seer.ufrgs.br/presenca 
saudáveis (pois a lei atinge a todos, e não apenas aos pais violentos); já temos toque de recolher em algumas cidades paulistas, proibindo a permanência de menores saudáveis na rua, após um determinado horário, sem a companhia do pai ou da mãe. Temos ainda a criminalização do aborto legislando sob o corpo de mulheres responsáveis e autônomas, e assim por diante. Percebo que o cidadão está cada vez mais cercado, cada vez mais administrado, com o seu consentimento.

Como efeito da presença cada vez maior do Estado na vida privada encontramos, diante de nossos olhos, adultos cada vez mais infantilizados. A permissão da intromissão do Estado, na vida privada, parece-me sinalizar a produção de sujeitos fracos, inibidos em suas capacidades para as decisões; sujeitos obedientes, dóceis e incapazes de refletir sobre seus próprios atos, haja vista a quantidade de publicações e programas televisivos de autoajuda: com a criação dos filhos, dos animais, das plantas; com o preparo dos alimentos, compra das roupas e assim por diante.

Por outro lado, tenho observado que, de fato, não estamos sabendo cuidar de nós mesmos. Os corpos dóceis da obediência, de que falava Foucault, já constituem uma realidade na contemporaneidade. A vigilância e a punição foram interiorizadas. Vivemos na sociedade do controle, como afirmam os pensadores pós-modernos. Não estamos sendo educados nem nos educando para sermos capazes de refletir sobre nós mesmos. O sujeito produzido pela sociedade do controle, em nós, é uma identidade incapaz de escolher por si o que the faz mal e o que lhe faz bem. As identidades produzidas pela sociedade do controle são representantes da máxima que diz: $o$ trabalho dignifica $o$ homem, entendendo trabalho como meio de ganhar o sustento no sistema capitalista. Essa identidade do trabalhador é uma representação que deseja se fixar. Desesperada, corre atrás do futuro, tal como o burro anda com a cenoura pendurada à sua frente. Essa identidade do trabalhador está sempre muito atarefada, trabalhando demais; trabalhando para que, perguntamos? Ele ou ela não sabem direito o que responder e lembram-se de

Carminda André, Arte, Biopolítica e Resistência.

R.bras.est.pres., Porto Alegre, v.1, n.2, p. 426-442, jul./dez., 2011.

Disponível em http://www.seer.ufrgs.br/presenca 
geladeiras, carros, sapatos, roupas, botox, viagra, colégio para as crianças, fazer o supermercado, etc.

Muito bem, vamos acreditar que a biopolítica, administradora da sociedade do controle, é uma política pela vida, pela vida saudável da população. Uma política que cuida. Não é em nome da vida que a medicina tem feito avanços extraordinários no campo da genética? Mas por que esse cuidado se não é para todos? Por que algumas vidas seriam dignas de serem preservadas e outras não? Por que certas vidas seriam mais expostas à morte do que outras? Seleção natural?

Na obra Em Defesa da Sociedade, Michel Foucault apresenta a ideia de que houve, em certo momento da história do ocidente europeu, a interiorização da guerra nos modos de organização social. De que teria havido um deslocamento do valor da guerra para a política interna, positivando-a, legitimando a própria guerra como um modo de governar e, por consequência, como modo de vida. Nas ex-colônias, como o Brasil, a guerra é princípio de dominação. Se fizéssemos um mito de origem da nação brasileira, poderíamos escrever sem pestanejar: no início era a guerra.

Hoje, não muito distante do que se chamou independência do Brasil, a política sobre a vida exportação do mundo europeu - ainda mantém a guerra. O que mudou foi a estratégia. Não mais precisamos das chibatas do colonizador para nos vigiar e punir, temos interiorizada a obediência; tornamo-nos vigias e carrascos de nós mesmos e dos que estão à nossa mão. Hoje, a guerra é continuada por outros meios, como nos ensina um insurgente, Michel Foucault. A guerra é justificada cientificamente. Arma-se um campo de guerra, guerra interna. Foi sob o signo da teoria das espécies que a guerra tornou-se princípio de sobrevivência no mundo moderno; tornou-se instinto; tornou-se natureza humana; tornou-se um modo ético de agir; e produziu a interiorização da eugenia como discurso verdadeiro. Foi com o discurso científico que se naturaliza o enunciado de que a natureza está aí para nos servir. Servir a quem?

Carminda André, Arte, Biopolítica e Resistência.

R.bras.est.pres., Porto Alegre, v.1, n.2, p. 426-442, jul./dez., 2011.

Disponível em http://www.seer.ufrgs.br/presenca 
É aí que entra o racismo como discurso fundamental para a perpetuação da guerra continuada por outros meios. E o que é racismo?

É, primeiro, o meio de introduzir afinal, nesse domínio da vida de que o poder se incumbiu, um corte: o corte entre o que deve viver e o que deve morrer. No contínuo biológico da espécie humana, o aparecimento das raças, a distinção das raças, a hierarquia das raças, a qualificação de certas raças como boas e de outras, ao contrário, como inferiores, tudo isso vai ser uma maneira de fragmentar esse campo do biológico de que o poder se incumbiu; uma maneira de defasar, no interior da população, uns grupos em relação aos outros. Em resumo, de estabelecer uma cesura que será do tipo biológico no interior de um domínio considerado como sendo precisamente um domínio biológico. Isso vai permitir ao poder tratar uma população como uma mistura de raças ou, mais exatamente, tratar a espécie, subdividir a espécie de que ele se incumbiu em subgrupos que serão, precisamente, raças. Essa é a primeira função do racismo: fragmentar, fazer cesuras no interior desse contínuo biológico a que se dirige o biopoder. De outro lado, o racismo terá sua segunda função: terá como papel permitir uma relação positiva, se vocês quiserem, do tipo: "quanto mais você deixar morrer, mais, por isso mesmo, você viverá" ou "se você quer viver, é preciso que você faça morrer, é preciso que você possa matar" (Foucault, 1999, p. 304-305).

À luz do racismo, inferioriza-se o outro como raça; o racismo normaliza a ação de policiais de elite invadindo favelas para limpar a área, torturar e matar jovens infratores com vida desqualificada; o racismo faz aceitável o enclausuramento dos desqualificados como forma de correção; só o racismo pode justificar o extermínio da cultura indígena sob a alegação de atraso cultural; só o racismo nos faz acreditar que certas etnias são mais suscetíveis ao crime.

O racismo - com seu poder de corte, de segregação social - gera medo com a presença do outro. Quase todos se tornam suspeitos. Isso nos priva de conhecer laços afetivos coletivos; priva-nos de ter o outro como parente; priva-nos da compaixão, se a compreendemos como a dor do outro sendo minha também. O racismo, de certa

Carminda André, Arte, Biopolítica e Resistência.

R.bras.est.pres., Porto Alegre, v.1, n.2, p. 426-442, jul./dez., 2011.

Disponível em http://www.seer.ufrgs.br/presenca 
maneira, nos salva de cair na dor que a realidade criada, sob seus princípios, produz.

É em virtude dessa naturalização do direito de deixar morrer como condição para fazer viver o mais forte, o escolhido, que penso que a arte pode tornar-se um meio para resistir, não pelo confronto, mas pela recusa de continuar a guerra. Recusar a continuar a alimentar práticas e dispositivos de poder que reproduzem a segregação, o separatismo, a desigualdade. Não porque se acredita na unidade e na igualdade. Tudo isso não passa de invenções históricas; de imagens, identidades elaboradas a partir de certo campo de forças discursivas. Mas para fazer outros usos do espaço, do corpo, dos discursos. Inventar relações afetivas como prática ética, reinventar modos de produzir afetos. O racismo impõe um modo de apropriação da natureza, dos corpos, dos saberes que empobrece as relações afetivas, os laços familiares, a solidariedade coletiva, enfim, empobrece a vida como espaço de trocas afetivas, de criações poéticas. O poder é inclusivo e se multiplica pela potência criativa que o refunda permanentemente.

Recuso-me a reproduzir esses hábitos, defendo outros usos para a natureza dos corpos e dos saberes, é essa a aposta que aqui realizo para poder seguir em frente, atuar como professora e continuar acreditando na transformação. Reinventar a vida em dimensões minúsculas, particulares, fora do espetáculo promovido pelo capitalismo, em sala de aula, é o que posso oferecer. Porém, não se trata de ações para a libertação do alienado, libertação das grades dos biopoder. Não mais acredito nisso. A revolução, nos moldes convencionais (heroica), não educa os indivíduos para a reflexão ética, mas impõe outra ordem, absolutiza outro modo de servidão quando esse não é uma escolha pessoal. A recusa aqui mencionada é a recusa à vida pobre, à vidasobrevivência, à vida de puro sacrifício para um futuro incerto, à vida só para acumular coisas. A recusa aqui é um pedido a valorizar o presente como o bastante para a vida.

Carminda André, Arte, Biopolítica e Resistência.

R.bras.est.pres., Porto Alegre, v.1, n.2, p. 426-442, jul./dez., 2011.

Disponível em http://www.seer.ufrgs.br/presenca 


\section{Arte e Recusa}

É impressionante o número de artistas que atuam nas ruas, nas praças, nos parques e outros lugares públicos na atualidade. O que estaria acontecendo?

No final do século XX, um autor desconhecido de codinome Hakin Bey publica, nos Estados Unidos, um pequeno livro chamado Zona Autônoma Temporária TAZ. A descrença nos Estados políticos modernos, a descrença em qualquer tipo de moralidade possível no capitalismo levou esse autor a pensar sobre outro modo de aproximar arte e política. Bey associa as festas raves e a atuação de hackers aos antigos piratas. Nômades e distantes das leis inglesas, os supostos malfeitores, os piratas, criaram modos de vida totalmente desvinculados a qualquer tipo de Estado-Nação. Para Bey, tanto as festas rave como os navegantes do cyberespaço, os hackers, criam espaços paralelos ao institucionalizado, com funcionamento singular e, na maioria das vezes, em oposição aos usos da moralidade estatal. As raves são vistas por Bey como lugares sem um tipo de organização disciplinar. Lugar em que o corpo é exposto a um tipo de música eletrônica, em alto volume, capaz de tirá-lo de seu ritmo cotidiano. Esse corpo hipersensibilizado, pela música e pelas drogas, comporta-se de modo não disciplinar, fora dos padrões de educação que o formatou. Em vez de pensar tais festas como alienantes, Bey vê ali a alternativa de experimentar outros possíveis do próprio corpo. Se entendermos o Corpo sem Órgão, descrito por Deleuze em Mil Platôs, como um corpo indisciplinado, ou seja, corpos expostos a situações transbordantes de limites (físicos, psicológicos, estéticos), experiências que abram percepções, desejos, prazeres; experiências que possibilitam reinventar comportamentos, sair dos padrões aprendidos no espetáculo midiático, na disciplinarização escolar, no adestramento biopolítico; se compreendermos o Corpo sem Órgãos como um corpo fora do discurso científico, corpo como subjetividade em devir, talvez as festas raves - bem como outras práticas corporais fora do padrão normativo do ocidente cristão - abram um campo de possibilidades para se repensar a ética, o sexo, as dietas, o corpo como estéticas de existência. Ou seja, de

Carminda André, Arte, Biopolítica e Resistência.

R.bras.est.pres., Porto Alegre, v.1, n.2, p. 426-442, jul./dez., 2011.

Disponível em http://www.seer.ufrgs.br/presenca 
pensar uma arte da sexualidade, da culinária e dietas, do corpo. Nesse sentido, penso que podemos aproximar a experiência das festas raves com algumas performances art em que o corpo do artista é submetido a situações de risco, de ultrapassamento de fronteiras, corpo-arte, com propósitos de fazer surgir outras subjetivações. Assim é, por exemplo, o trabalho de Marina Abramovic e outras performers que trabalham com os limites da arte e suas resistências.

O fato de tais festas serem consideradas práticas inimigas da sociedade já nos sinaliza uma resistência a certo discurso sobre a ética, a sexualidade, uso das drogas e do corpo. Tanto a festa como o navegante cibernético desterritorializam. Isso coloca em alerta os dispositivos de poder espalhados por todo o cotidiano, práticas que integram a um discurso que defende o mapeamento de todos os lugares e sua vigilância. A desterritorialização torna-se uma ação suspeita e, em curto prazo, é criminalizada pelos saberes-poderes que apostam da vida como fixação.

A arte como recusa a práticas de racismo sinaliza o desejo de deixar morrer os Estados-nações, o capitalismo, o discurso racista da biopolítica, mas sem o confronto, sem a revolução como meio. Bey inicia seu livro criticando a ideia de revolução para, assim, nos apresentar a atitude do insurgente, do rebelde independente. A revolução é compreendida como o resultado de um confronto entre forças, é o fim de um ciclo em que um Estado é atacado e se instaura outro Estado. Bey não mais parece acreditar nesse tipo de ação política e assume um discurso de desnaturalização da História como a sucessão de revoluções, supostamente em progressão, de Estados em Estados. Bey evidencia, então, que não está propondo rupturas revolucionárias, que não está propondo a mudança da consciência dos indivíduos. Fala, no entanto, em ação política e estética na forma de levante. Para o autor, ações de levante são momentos de recusa radical, são manifestações do que é proibido, temporário, são experiências de pico. Não é algo que se faz todos os dias, mas, quando ocorre, o levante gera não uma mudança de consciência, e sim uma

Carminda André, Arte, Biopolítica e Resistência.

R.bras.est.pres., Porto Alegre, v.1, n.2, p. 426-442, jul./dez., 2011.

Disponível em http://www.seer.ufrgs.br/presenca 
diferença. A mudança de consciência pressupõe a transformação dos modos de pensar do sujeito, modos esses que geram sua práxis. Isso quer dizer que o sujeito estava atrelado a uma certa identidade alienada e que, ao tomar consciência desse estado, desloca seu objeto de identificação para outro.

A diferença é a afirmação de outros possíveis para o corpo, para a subjetividade, para a arte, para a vida. $\mathrm{O}$ levante é uma ação que aparece fora do tempo da história das revoluções, uma ação que não é originária da continuidade da história das revoluções, que não é também seu oposto ou sua crítica direta. O levante é aqui compreendido como ação de quem pensa diferente do que se instituiu no regime de verdades legitimado e instituído socialmente (pela academia, pelos partidos políticos, pelas corporações econômicas, pela moralidade cristã, pela família).

$\mathrm{O}$ insurgente é alguém que pensa e propõe viver fora. Mas, como o fora não existe em um mundo totalmente mapeado, esse fora deverá ser inventado. Para isso, muitos artistas insurgentes saem à procura de espaços, buracos, fendas no mapa urbano para experimentar novos possíveis. Quando descobertos, esses insurgentes são expostos à penalização. Por exemplo, uma subjetividade que não pode ser definida como homem ou mulher, é uma subjetividade insurgente, suas práticas sexuais saem da norma que divide a humanidade pela genitália: macho/fêmea. Uma mulher, heterossexual, que não tem filhos, mas tem uma situação amorosa estável, não está inserida na norma de que a natureza feminina só se completa com a maternidade. É nessa perspectiva do insurgente que compreendo algumas ações artísticas realizadas em ruas, praças, casas abandonadas, bueiros, túneis e outras fendas achadas.

Vou aqui me referir a certos tipos de intervenção urbana, aquelas que não são identificáveis a partir da categorização estética e acadêmica que divide as artes em: artes visuais, teatro, dança, cinema, música etc. É difícil e inútil buscar definir a qual categoria estética algumas intervenções artísticas urbanas pertencem. Elas são ações insurgentes e, por isso, não são resultantes da

Carminda André, Arte, Biopolítica e Resistência.

R.bras.est.pres., Porto Alegre, v.1, n.2, p. 426-442, jul./dez., 2011.

Disponível em http://www.seer.ufrgs.br/presenca 
história da arte, posto que essa também segue a lógica das revoluções estéticas. Os artistas insurgentes estão entre as fronteiras espaciais e suas definições.

Entendo que algumas intervenções urbanas são também ações políticas do gênero ativista. Não são, portanto, ações de confronto direto com o Estado. Para Hakin Bey, esse confronto não interessa (pois não the interessa o poder, estar no poder, ser Estado). O confronto com o Estado não vale a pena, pois este é tratado como um Estado terminal, uma megacorporação/Estado de informações, como império do Espetáculo e da Simulação, tudo o que não se deseja perpetuar.

Bey apresenta uma imagem muito interessante do Estado e seus representantes, tais como a polícia. Tem consciência de que todos os seus revólveres estão apontados para nós, mas, por outro lado, em sua percepção de insurgente, com seu armamento miserável (balões, roupas de palhaços, instrumentos musicais, bandeiras, palavras em estado de poesia, enfim), Bey garante que não tem em quem atirar, pois está diante de um uniforme vazio. $\mathrm{O}$ Estado e suas representações são percebidos como simulacros, como fantasmas vestidos de policial, de políticos, de jornalistas, de gerentes etc. Também os pensadores pós-modernos - Foucault, Deleuze, Lyotard - compartilham dessa ideia dos fantasmas; das identidades como criações fantasmagóricas. Um policial, um médico, um padre, são personagens, representações de rostos fixos; assim é que compreendo serem também fantasmas. Não se identificar com um rosto é não fixar, em forma, a potência da subjetividade em nós.

\section{Ação Independente}

O levante proposto por Bey é anarquista. A ação cria o que chamou de Zonas Autônomas Temporárias, isso quererá dizer que se trata de ocupações clandestinas de espaços em que o Estado ainda não reconheceu a ação dos rebeldes ou que está momentaneamente vazio de armamentos (câmeras de segurança, guarda metropolitana, delatores civis). 
Não confrontar com o Estado, diretamente, quer dizer atuar com o maior grau de invisibilidade, atuar de modo a não ser facilmente definido. Adquirir uma identidade no Espetáculo do capitalismo é o mesmo que ser capturado. Por exemplo: como definir a ação dos pixadores?

Assim que a TAZ é nomeada (representada, mediada) ou descoberta por policiais, ela deve desaparecer, ela vai desaparecer, deixando para trás um invólucro vazio, e brotará novamente em outro lugar, novamente invisível, porque é indefinível pelos termos do Espetáculo. [...] A TAZ é um microcosmo daquele "sonho anarquista" de uma cultura de liberdade. [...] A TAZ é um acampamento de guerrilheiros ontologistas: ataque e fuga. A TAZ deve ser capaz de se defender; mas, se possível, tanto o "ataque" quanto a "defesa" devem evadir a violência do Estado, que já não é uma violência com sentido. $\mathrm{O}$ ataque é feito às estruturas de controle, essencialmente às ideias. [...] $\mathrm{A}$ 'máquina de guerra nômade' conquista sem ser notada e se move antes do mapa ser retificado (Bey, 2004, p. 18-19).

Todas as frases acima, destacadas do livro de Bey, podem nos indicar do que se trata a TAZ.

A TAZ surge também do que Bey chama de "fechamento do mapa". Isso quer dizer que não há no globo terrestre um território que não seja tomado por uma nação-Estado. Ao que o autor chama de "gangsterismo territorial" onde,

[...] nenhum centímetro quadrado da Terra está livre da polícia ou dos impostos... em teoria. [...] O mapa está fechado, mas a zona autônoma está aberta. Metaforicamente, ela se desdobra por dentro das dimensões fractais invisíveis à cartografia do Controle (Bey, 2004, p. 22).

Quanto a se pensar a arte, cito Bey: “[...] a TAZ deseja, acima de tudo, evitar a mediação, experimentar a existência de forma imediata" (Bey, 2004, p. 34). Pensemos no teatro em sua forma moderna: narrativa dramática, personagens, encenação etc. Essa arte está engajada no propósito de representar um aspecto da realidade para o público. A cena (o espetáculo) serve

Carminda André, Arte, Biopolítica e Resistência.

R.bras.est.pres., Porto Alegre, v.1, n.2, p. 426-442, jul./dez., 2011.

Disponível em http://www.seer.ufrgs.br/presenca 
como mediador entre público e o que supostamente estamos chamando de realidade. Não estamos diante da realidade diretamente. Assistimos a peças que falam sobre o sistema carcerário, sobre a vida nas favelas de alguma grande cidade do Brasil, sobre os conflitos entre gerações em uma família de classe média e assim por diante. Mas não estamos experimentando prisão, favela, sala burguesa para uma ressignificação sentimental desses lugares; vemos esses lugares por meio de um espelhamento. Isso é o que compreendo por mediação. Algumas performances art (incluindo as intervenções urbanas) não representam a realidade. Isso não significa ser contra a arte da representação. Simplesmente, certos tipos de manifestações artísticas contemporâneas não se originam do discurso moderno, que define a arte como representação da realidade. A arte é presença de algo que não estava antes; não se trata de revelação de algo que se escondia, mas de tornar presente um vir a ser ali flutuante. Quando o jogo artístico acontece, a arte inventa realidades. A arte é signo exposto para contemplar diferentes usos.

No entanto, não é o caso de presentificar algo que foi descoberto pelo artista. Não observo, em grande parte da produção vanguardista da arte contemporânea, desejo de eliminar a arte da representação. Mesmo porque não há linguagem sem representação, não há vida coletiva sem representação.

$\mathrm{O}$ que fazem os artistas radicais da contemporaneidade é não perpetuarem a história das revoluções estéticas, eles não desejam a guerra. Não há disputa de poderes; não há desejo de um lugar ao sol nessa cartografia de pátio de cárcere. $O$ sonho do insurgente, como aqui estamos o definindo, é inventar outros modos de pensar e viver os espaços; é criar outra dimensão; é trabalhar na concretude do virtual. Virtual não como escape, como sonho, como irreal ou falso; virtual como outros possíveis para a vida. Admitir a guerra, buscar um lugar social nessa cartografia panótica, é admitir o cárcere (controle) como único modo de vida.

A ação insurgente, que menciono aqui, desordena as sistematizações, embaralha as identidades, faz outros

Carminda André, Arte, Biopolítica e Resistência.

R.bras.est.pres., Porto Alegre, v.1, n.2, p. 426-442, jul./dez., 2011.

Disponível em http://www.seer.ufrgs.br/presenca 
usos do espaço; intervém no ritmo dos transeuntes, nos comportamentos disciplinados dos lugares em que se apresentam. Para insurgir é preciso conhecer a cartografia oficial e a cartografia dos andarilhos, dos camelôs, dos traficantes. $O$ artista interventor não reconhece as fronteiras das identidades, da população dividida em classes.

Da minha perspectiva, alguns tipos de intervenção urbana não definem uma categoria estética. Sua presença pode acontecer, tomando de empréstimo várias formas estéticas. Tudo depende do que seus criadores conseguem agenciar no momento da ação, tudo o que necessitam para se disfarçar. Nesse sentido, entendo que certos tipos de intervenção urbana são modos de resistir à espetacularização da vida, sua homogeneização.

Muitos artistas de rua me parecem pacifistas que, ao deixar de fazer o jogo da guerra como meio de vida, tornam-se um inimigo do Estado. Como é isso? Não estando em um lugar fechado (galerias, teatros, casas de show, espaços alternativos fechados), muitos artistas de rua vivem como mendigos, despossuídos (desempossados) e, com isso, afirmam um modo de vida nômade. Na sociedade do controle, em que os lugares públicos estão fortemente armados - com instrumentos de controle dos comportamentos, controle dos usos do espaço, controle do caminho do transeunte - a errância dos moradores de rua, dos mascates, dos artistas de rua torna-se ruído, ameaça à permanência da ordem para os ouvidos do biopoder. No entanto, isso tudo é cena, pois o que pode um mendigo? De quais armas pode dispor um andarilho? Viver como despossuído é um exercício de desvalorização da propriedade privada; saber que é possível a vida fora da lógica produtivista é o que causa pavor. O trabalho em ruas-praças-faróis interpretado como negação do trabalho dentro de estabelecimentos juridicamente reconhecidos, como negação da regulamentação profissional ou comercial exigida pelo poder público, é uma estratégia discursiva, que faz virar realidade aquilo que enuncia. O que o poder panótico não suporta é o uso aleatório que a população possa vir a

Carminda André, Arte, Biopolítica e Resistência.

R.bras.est.pres., Porto Alegre, v.1, n.2, p. 426-442, jul./dez., 2011.

Disponível em http://www.seer.ufrgs.br/presenca 
fazer dos espaços públicos, usos sem autorização; o uso sem o controle é o que causa terror e gera violência.

$\mathrm{O}$ artista de rua, como qualquer trabalhador despossuído, utiliza o espaço da rua para sobreviver, pois precisa do encontro coletivo para realizar o que deseja. Privatiza o espaço público? Não, porque é nômade. Seu estado de espírito, seu psiquismo, seu modo de vida, é nômade; vive entre as fronteias. Por isso, são criadores de TAZ. Uma vez descobertos, eles desaparecem para ressurgir em outra fresta que irão inventar.

\section{Arte e Política}

Aproximo certa arte urbana ao ativismo político. Diferencio a intervenção urbana da arte política partidária que tem por finalidade propagar a revolução socialista, tal como o teatro de agitação e propaganda russo, o teatro do oprimido de Augusto Boal, o teatro épico de Brecht e outros. A arte, que se propõe ativista, é a expressão de quem sonha o sonho anarquista e, por isso, seus coletivos - compostos por pessoas de diferentes formações (artistas, biólogos, engenheiros, professores) - buscam um modo de organizar as ações sem um líder. Nesse sentido, a internet é, talvez, sua maior ferramenta.

Os artistas insurgentes não pedem autorização ao poder público para se manifestar. Não fazem isso para insistirem na livre expressão, pois não mais acreditam nessa democracia que aí está. Sabem que o que fazem está sob o signo do proibido e que a liberdade é, também, algo que consumimos e que logo terá que se reembalada, com nova fórmula.

Vejamos, por exemplo, o artista plástico Alexandre Orion, que apenas com pano e água faz sua arte nas paredes sujas de fumaça em um túnel na cidade de são Paulo. Pinta caveiras. Os artistas ativistas atuam clandestinamente, sua força em desordenar está em sua invisibilidade. Intervir não é somente aparecer em um lugar imprevisível, intervir é embaralhar o conceito de harmonia estética imposta pelo poder.

Vou dar outro exemplo de uma intervenção em que estive presente e que, ao mesmo tempo em que a performer propôs uma relação política horizontal (para

Carminda André, Arte, Biopolítica e Resistência.

R.bras.est.pres., Porto Alegre, v.1, n.2, p. 426-442, jul./dez., 2011.

Disponível em http://www.seer.ufrgs.br/presenca 
realizar sua cena precisava da atuação do transeunte), fez com que o espectador-participante explicitasse um comportamento ético que o deixou desconcertado.

Trata-se do que chamamos de barraca de trocas. Esse jogo artístico, na rua, suscita uma reação curiosa nas pessoas: testa nossos princípios éticos. Distribuímos vários tipos de objetos nessa barraquinha e trocamos por outros objetos.
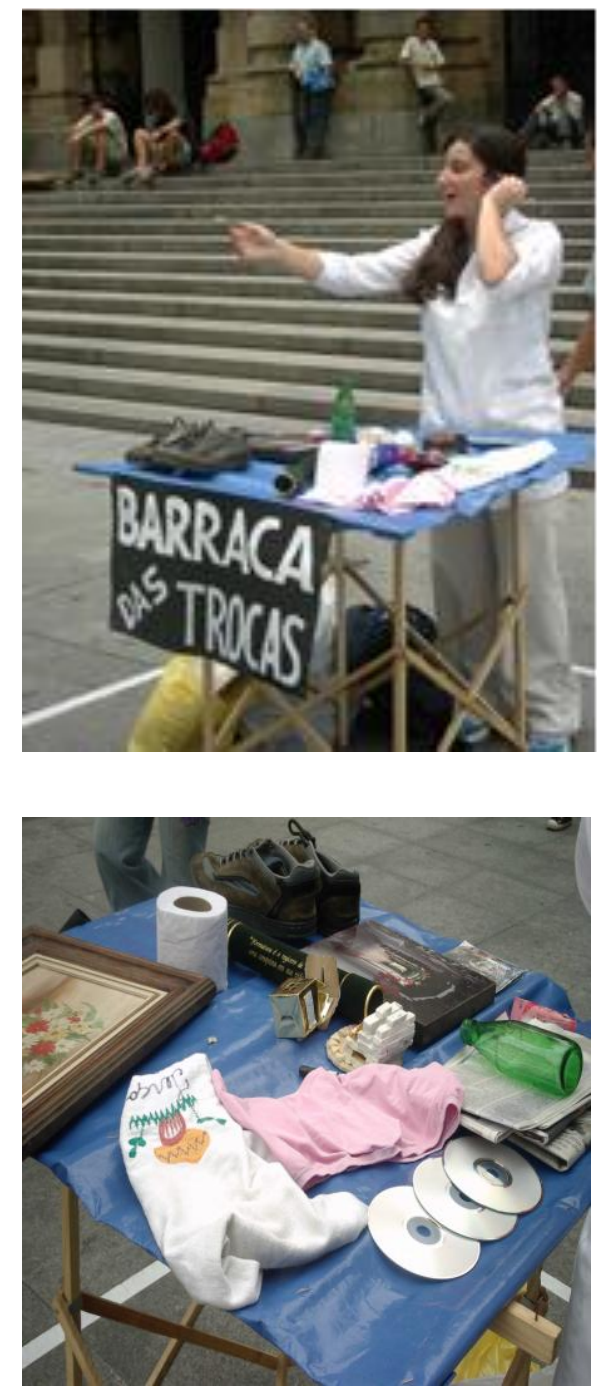

Performer: Milene Valentir

Nesse dia da foto (acima), o jogo era trocar os objetos sem qualquer tipo de restrição. Um dos pedestres parou e nos desafiou da seguinte maneira, escolheu uma caixinha de música que funcionava muito bem e quis

Carminda André, Arte, Biopolítica e Resistência.

R.bras.est.pres., Porto Alegre, v.1, n.2, p. 426-442, jul./dez., 2011.

Disponível em http://www.seer.ufrgs.br/presenca 
trocar por uma caneta velha que tinha no seu bolso. Fez isso sorrindo, já esperando nossa negativa. Qual foi sua surpresa quando nossa jogadora, a artista e educadora Milene Valentir, com um belo sorriso, aceitou a caneta e entregou o objeto escolhido ao sujeito. Ele ficou surpreso, depois envergonhado, pois queria desfazer a troca, alegando que nosso objeto valia muito mais do que aquele que ele nos dera - a destroca foi efusivamente negada pela artista. Ele tinha que ficar com seus sentimentos, responsável por sua ação. Então, maravilhado e com olhos marejados, o sujeito lançou um olhar poético para nossa artista e, como se visse nela algo de grandeza invisível, só teve a nos oferecer um deus te abençoe. Talvez aquelas palavras, inundadas de sentido, tenha sido o bem mais precioso que trocamos naquele dia. O que ele pôde nos oferecer, com a experiência ética, foi sua fé na possibilidade de haver ainda uma relação de troca em que os valores sejam subjetivos, e não somente econômicos.

Em seus aspectos formais, certa produção de arte urbana é constituída por tudo e todos que estão nas ruas: tipo de urbanismo, obras de arte públicas, ambulantes, moradores de rua. Tenho dificuldade em catalogar barraca de trocas dentro das classificações convencionais das artes. A beleza da barraca de trocas não está na cena que o artista ensaia para mostrar aos espectadores; nem na manufatura de seus objetos; nem na mimese; sua beleza está na experiência ética que o jogo artístico propõe; a beleza está na proposição de uma outra possibilidade estética para as relações entre indivíduos. Por meio da arte algo aconteceu, pois deslocou os valores dos indivíduos envolvidos, os fez repensar o que é valor através da própria escolha do objeto.

A estrutura de um jogo interativo como esse precisa ser móvel, permeável; um jogo que precisa da presença do outro, presença física, presença de espírito, presença de participação efetiva.

As intervenções urbanas não visam à estetização do cotidiano das cidades, apesar de poderem resultar nisso. No entanto, sua presença reinventa beleza onde encontramos péssimas condições de conservação dos

Carminda André, Arte, Biopolítica e Resistência.

R.bras.est.pres., Porto Alegre, v.1, n.2, p. 426-442, jul./dez., 2011.

Disponível em http://www.seer.ufrgs.br/presenca 
lugares; sua presença contrasta com a feiura que se reproduz no cotidiano. Cidades enfeiadas que exibem vidas enfeiadas.

A arte é um campo de difícil atuação. A população não quer se aproximar de mais feiura, de mais violência, de maus tratos. Quando os artistas realizam uma ação que parece suspeita aos olhos da população, logo são denunciados por algum cidadão e logo são abordados por policiais. Mas há ações artísticas em que a população não os denuncia, ao contrário, os protege. Gosto de pensar que isso acontece porque tais indivíduos conseguiram comungar de alguma utopia, comungar algo que não queremos fazer morrer: outra vida possível, outras relações possíveis entre as pessoas, uma existência bela.

\section{Referências}

BEY, Haken. Zona Autônoma Temporária. 2. ed. São Paulo: Conrad, 2004. (Coleção Baderna)

DELEUZE, Gilles. Mil Platôs: capitalismo e esquizofrenia. v. 3. São Paulo: Ed. 34, 1996.

FOUCAULT, Michel. Em Defesa da Sociedade. São Paulo: Martins Fontes, 1999. (Coleção Tópicos)

Carminda Mendes André é doutora em Educação pela Universidade de São Paulo. É professora na área de Artes Cênicas na Universidade Estadual Paulista "Júlio de Mesquita Filho" - UNESP, em São Paulo.

E-mail: carminda.stenio@uol.com.br

Recebido em Julho de 2011

Aprovado em Setembro de 2011

Carminda André, Arte, Biopolítica e Resistência.

R.bras.est.pres., Porto Alegre, v.1, n.2, p. 426-442, jul./dez., 2011.

Disponível em http://www.seer.ufrgs.br/presenca 